\title{
Insecticide resistance status of the Anopheles funestus population in Central African Republic: a challenge in the war
}

Marina Lidwine Olé Sangba ${ }^{1,2}$, Tanguy Deketramete ${ }^{1,3}$, Solange Patricia Wango ${ }^{3}$, Mirdad Kazanji ${ }^{4}$, Martin Akogbeto ${ }^{2,5}$ and Mamadou Ousmane Ndiath ${ }^{1 *}$

\begin{abstract}
Background: In the Central African Republic, malaria is a major public health problem and the leading cause of death among children. This disease appears to be hyperendemic but no substantial entomological data, including data on Anopheles spp. susceptibility to insecticides, is available. This study evaluates, for the first time in the CAR, the status of insecticide resistance in the Anopheles funestus population, the second major vector of malaria in Africa.

Methods: WHO standard bioassay susceptibility tests were performed on the An. funestus population using F1 generation from gravid females mosquitoes (FO) collected by manual aspirator sampling of households in Gbanikola, Bangui in October 2014 to assess: (i) An. funestus susceptibility to bendiocarb, malathion, permethrin, lamda-cyhalothrin, deltamethrin and DDT, and (ii) the effect of pre-exposure to the piperonyl butoxide (PBO) synergist on insecticide susceptibility. Additional tests were conducted to investigate metabolic resistance status (cytochrome P450 monooxygenases, glutathione S-transferases, and esterases).
\end{abstract}

Results: A high phenotypic resistance of An. funestus population to malathion, DDT and pyrethroids was observed with a mortality rate ranging from 23 to $74 \%$. For the pyrethroid groups, the mortality rate was 35,31 and $23 \%$ for lambda-cyhalothrin, deltamethrin, and permethrin, respectively. In contrast a $100 \%$ mortality rate to bendiocarb was recorded. Knockdown time (KDT) was long for all pyrethroids, DDT and malathion with $\mathrm{KDT}_{50}$ higher than 50 min. Pre-exposure of An. funestus to PBO synergist significantly restored susceptibility to all pyrethroids (Fisher's exact test $P<0.0001$ ) but not in DDT (Fisher's exact test $P=0.724$ ). Data from biochemical tests suggest the involvement of cytochrome P450 monooxygenases, esterases and glutatione S-transferases in the resistance of An. funestus population from Gbanikola (Wilcoxon test $P<0.05$ ).

Conclusion: Evidence of biochemical resistance to insecticide was detected in An. funestus population from the district of Gbanikola, Bangui. This study suggests that detoxifying enzymes are involved in insecticide resistance of An. funestus. However, despite disruptive violence, further research is urgently needed to assess the insecticide susceptibility status of An. funestus population in all CAR regions; insecticide resistance could rapidly compromise the success of malaria control programs.

Keywords: Malaria, Anopheles funestus, Insecticide resistance, kdr, Bangui, Central African Republic

\footnotetext{
* Correspondence: ousmane.ndiath@gmail.com

'G4 Malaria Group Institut Pasteur in Bangui, Bangui, Central African Republic

Full list of author information is available at the end of the article
} 


\section{Background}

Despite considerable efforts during the past decade, malaria remains a major public health issue, particularly in Africa [1]. In the Central African Republic (CAR), malaria appears as hyperendemic and in 2013 more than 262,000 people suffering from this disease were treated by Doctors Without Borders teams (MSF) and it also appears to be the cause of a large number of hospital deaths [2]. The mortality rate in the country is generally higher than the "emergency threshold"; this is due to a failing health care system. According to Doctors Without Borders, the CAR has the second lowest life expectancy in the world, i.e. 48 years [3]. In July 2006, the CAR National Malaria Control Programme implemented the first phase of Global Fund Programme for Malaria activities during the period 2006-2009 based on a free LLINs distribution to pregnant women and children under five, with no significant success. Free access to health care and malaria vector control (IRS) are far from being a reality [3-5]. The country is plagued by shortages of essential drugs, logistical constraints and political violence.

Today, there is almost unanimous agreement that the fight against malaria depends largely on an early diagnosis through rapid diagnostic tests (RDTs), cases management by artemisinin-based combination therapy (ACT), combined with vector control using long-lasting insecticidal bednets (LLINs) and indoor residual spraying (IRS) [6]. Pyrethroids are the only group of insecticides currently approved for treating bednets [7, 8], and several studies have demonstrated the efficacy of both (LLINs) and (IRS) for curbing malaria incidence [9-11]. However, these tools are threatened by the emergence of insecticide resistance. Reduced susceptibility to pyrethroids has been confirmed in mosquitoes in west, central, and east Africa and over 60 countries have reported resistance to at least one insecticide and some reported resistance to all insecticide classes (carbamate, organophosphate, pyrethroids and organochlorine) $[12,13]$, which may contribute to malaria rebound $[11,14]$. But in the CAR, no data on the status of malaria vector insecticide resistance are available.

Therefore an entomological study conducted between 2006 and 2010 on the epidemiology of yellow fever, highlighted a specific diversity of Aedes and other malaria vectors [15]. The presence of several malaria vectors are recorded with the high prevalence of Anopheles funestus, a major vector of malaria throughout much of subSaharan Africa. The highly anthropophilic and endophilic behaviour of this mosquito makes it an efficient vector of malaria, and in many regions, entomological inoculation rate (EIR) of $A n$. funestus far surpasses that of Anopheles gambiae $[11,16]$. In addition, in several African regions, resistance to insecticides in $A n$. funestus population has experienced a rapid increase in recent years [17-21] and represents a threat for malaria control efforts [1].
Recently between October and December 2013, an entomological study of malaria vectors conducted in several districts of Bangui showed the role of An. funestus in global malaria transmission including Gbanikola, a district of the capital city Bangui [22]. However, no studies have been conducted so far to investigate the mechanism, level, and types of insecticide resistance in the An. funestus population present in the CAR. In this context, we investigated the status of insecticide resistance in An. funestus population from Gbanikola and also explored the underling resistance mechanisms. This information will contribute to fill the gap in our knowledge and help to improve future vector control programs in the CAR.

\section{Methods}

\section{Study area}

The CAR is a country of Central Africa with a vast territory of $622,984 \mathrm{~km}^{2}$, surrounded by Cameroon to the west, Chad to the north, Sudan and Southern Sudan to the east, and the Democratic Republic of Congo (DRC) and the Republic of Congo to the south. The Ubangi and Mbomou Rivers form most of the southern border with the DRC. The northern part of the country is the high basin of the Chari River. The CAR suffers from frequent flooding due to lack of maintenance of rivers and impressive flow engendered by the rainy season. Most parts of the country are dominated by a tropical climate with a wet season from May to October and a dry season from November to April. Malaria transmission is perennial; all regions of the country are exposed to endemic malaria, with a peak during the rainy season. The district of Gbanikola (N 04 20.436'; E 018 32.213') is located southeast of Bangui, on the marshy bank of permanent stream. The anopheline larval sites were present all year round. The population was estimated at 4890 inhabitants in 2014. The average annual temperature is around $25^{\circ} \mathrm{C}$ and the average rainfall in October (the middle of the rainy season) is $400 \mathrm{~mm}$. During the second week of July 2014, 40 randomly selected households were visited for LLINs coverage. Ownership of bednets in the study population was $66 \%$ and over $70 \%$ of bednets were in a very poor state (holed and ripped).

\section{Mosquito collection and molecular identification}

Mosquitoes were collected in October 2014 during the rainy season in Gbanikola District, Bangui (Fig. 1). All Anopheles females used were morphologically identified as belonging to the An. funestus according to the key [23]. Two hundred fifty eight blood-fed $A n$. funestus were collected from living rooms at early morning between 6 and 11 am using a manual aspirator and flashlights. The offspring of An. funestus females (F0) were pooled and bred under the standard insectary conditions at the insectary of Institut Pasteur of Bangui to retrieve eggs. These eggs 


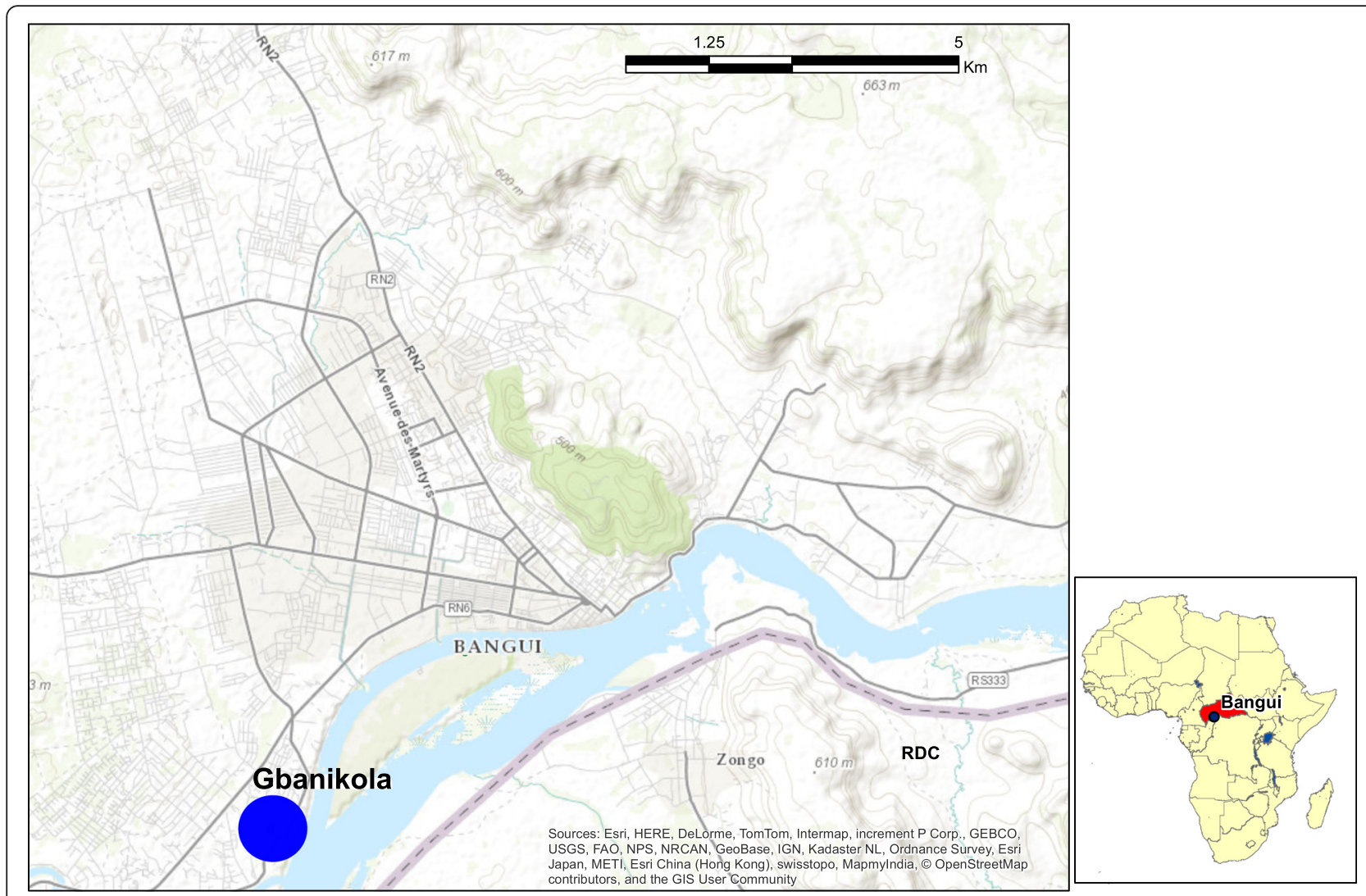

Fig. 1 Map of Bangui (Central African Republic) showing study Gbanikola district

were subsequently placed in water under the same conditions. Larvae were fed Tetramin fish food. Pupae were collected and placed in $10 \mathrm{l}$ plastic buckets, which were covered with mosquito gauze with a cotton sleeve for introducing $10 \%$ glucose on filter paper. Adults were maintained at $28{ }^{\circ} \mathrm{C}, 80 \%$ relative humidity and a $12: 12 \mathrm{~h}$ light:dark cycle. Unfed 2-3 day females An. funestus (F1) were used for insecticide tests. A polymerase chain reaction (PCR) analysis was used to confirm that all F0 females collected were exclusively An. funestus [24].

\section{Susceptibility assays}

Bioassays were carried out using WHO test kits for adults mosquitoes [25], to assess the level of sensitivity (or resistance) of mosquitoes to insecticides. Six insecticides of technical grade quality were used: three pyrethroids (permethrin $0.75 \%$, lambda-cyhalothrin $0.05 \%$, deltamethrin $0.05 \%$ ), one organochlorine (DDT $4 \%$ ), one organophosphate (malathion $5 \%$ ) and one carbamate (bendiocarb $0.1 \%$ ). Impregnated papers were obtained from the WHO reference center (Vector Control Research Unit, University Sains Malaysia, Penang, Malaysia). Four batches of 25 unfed females, aged 2-3 days, were exposed to the diagnostic doses of insecticide treated papers for $60 \mathrm{~min}$ at $26 \pm 1{ }^{\circ} \mathrm{C}$ and $80 \%$ relative humidity. The number of knockdown (KD) mosquitoes was recorded at $10,15,20,30,40,50$ and 60 min post-exposure. After exposure, mosquitoes were kept in observation tubes and supplied with a $10 \%$ sugar water solution. Expression of final mortality was measured $24 \mathrm{~h}$ after exposition. In the absence of An. funestus susceptible strain for a positive control, the An. gambiae Kisumu strain was used. Mosquitoes exposed to untreated papers were used as the negative control. For each insecticide, a sample of $15 \mathrm{An}$. funestus specimens was randomly selected, including the same number of dead and surviving specimens (when available) and used for molecular tests.

\section{PBO synergist assays}

In the event of confirmed insecticide resistance, additional bioassays were performed using synergist molecule for understanding metabolic processes involved in the detoxification of insecticides. In the case of DDT and pyrethroids, piperonyl butoxide (PBO synergist) was used to inhibit the specific activity of cytochrome P450 (monooxygenases P450). Unfed 2-3 day-old female $A n$. funestus (F1) were first exposed for $1 \mathrm{~h}$ to $4 \% \mathrm{PBO}$. After $\mathrm{PBO}$ exposure, mosquitoes were immediately exposed to deltamethrin $0.05 \%$, permethrin $0.75 \%$, lambda-cyhalothrin $0.05 \%$ and DDT $4 \%$ for another 
hour. For each insecticide, two batches of 25 females were exposed. Another batch exposed only to $\mathrm{PBO}$ was used as a control. The number of KD mosquitoes was recorded at $10,15,20,30,40,50$ and $60 \mathrm{~min}$. Mosquitoes were then transferred into holding tubes and supplied with a $10 \%$ sugar solution. Final mortality was assessed $24 \mathrm{~h}$ after exposure. Resistant and susceptible mosquitoes were preserved separately in eppendorf tubes filled with desiccated silica gel and used for molecular tests.

\section{Biochemical enzyme assays}

A total of 78 to $90 \mathrm{~F} 1 \mathrm{An}$. funestus (non-exposed to insecticide) stored at $80{ }^{\circ} \mathrm{C}$ were used for biochemical tests. The objective of these tests was to measure the activity of detoxification enzymes revealed by spectrophotometry. Activity levels of cytochrome P450, non-specific esterases (NSE), and glutathione S- transferases (GST) were calculated according the protocol described by Brogdon et al. [26] and by Hemingway et al. [27]. In short, females were homogenized individually in $100 \mu \mathrm{l}$ of $0.01 \mathrm{M}$ potassium phosphate buffer, $\mathrm{pH} 7.2$, and suspended in $1 \mathrm{ml}$ of buffer. Aliquots of $50 \mu \mathrm{l}$ were then transferred to microtiter plate wells. Thirty mosquitoes were analyzed per plate in triplicate. Replicates with a variation coefficient that were higher than 0.20 were discarded in order to avoid differences produced by any possible manual errors. All enzymatic reactions were conducted at room temperature. NSE levels were measured at $540 \mathrm{~nm}$ after $10 \mathrm{~min}$ incubation with $3 \mathrm{mM} \beta$-naphthyl acetate. The concentration of the final product (activity per mg of protein) was determined as an endpoint calculated from standard curve of $\alpha$ naphthyl acetate. For the cytochrome P450 assay, absorbance was measured at $620 \mathrm{~nm}$ after $5 \mathrm{~min}$ incubation with

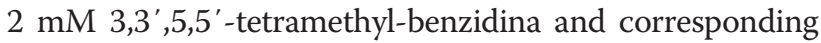
values of enzymatic activity per $\mathrm{mg}$ of protein were calculated from a standard curve of cytochrome c. GST levels activity were measured at $340 \mathrm{~nm}$ after 5 min incubation in the reaction containing $2 \mathrm{mM}$ reduced glutathione and $1 \mathrm{mM}$ 1-chloro-2,4-dinitrobenzene. An extinction coefficient of $5.76 \mathrm{mM}^{-1}$ (corrected for a path length of $0.6 \mathrm{~cm}$ ) was used to convert absorbance values to moles of product. GST specific activity was reported as the rate of formation of GSH produced in mmol. $\mathrm{min}^{-1} \cdot \mathrm{mg}^{-1}$ protein. Six negative controls (An. gambiae Kisumu strain) per plate were used. Absorbance was measured using a spectrophotometer type "Multiskan FC and Skanit Software" and the adjusted enzymatic mean activity of An. funestus was compared to the Kisumu susceptible strain.

\section{DNA extraction and PCR amplification}

DNA was extracted from individual mosquitoes using DNAzol essentially according to the manufacturer's recommendations (Invitrogen, CA, USA). The total genomic DNA from each mosquito was re-suspended in $100 \mu \mathrm{l}$
$\mathrm{H}_{2} \mathrm{O}$ and stored at $-20{ }^{\circ} \mathrm{C}$ until use. All F0 An. funestus population were identified by the PCR as described by Cohuet et al. [24]. Briefly, the ITS2 and D3 regions of the rDNA were amplified from $20 \mathrm{ng}$ of template DNA in $50 \mu \mathrm{l}$ reaction mixture containing $5 \mu \mathrm{l}$ of $10 \times$ reaction buffer (Qiagen), $1.5 \mathrm{mM} \mathrm{MgCl}, 200 \mu \mathrm{M}$ each deoxynucleotide triphosphate (Eurogentec), 0.5 units of Taq DNA polymerase (Qiagen), and $20 \mathrm{pmol}$ each of forward and reverse primers.

\section{Data analysis}

WHO [25] criteria were used to evaluate the resistance susceptibility status of the tested mosquito populations (98-100 \% mortality indicates susceptibility and < $98 \%$ mortality indicates that further investigation is required to confirm resistance). Fifty and 95\% knockdown times (respectively $\mathrm{KDT}_{50}$ and $\mathrm{KDT}_{95}$ ) were computed with probit regression models. Mortality rates were compared using Fisher's exact test. Biochemical assay data activities (enzymatic activity per mg of protein) of wild specimens of $A n$. funestus were compared between the reference strain (An. gambiae Kisumu) by Wilcoxon nonparametric and Kruskal-Wallis tests. Statistical analyses were performed using Stata 10.1 software. A $P$-value of 0.05 or less was considered as significant.

\section{Ethics approval}

This study was approved by the National ethics committee of Central African Republic: Authorization No 0101 MSANP/CNE2013.

\section{Results}

\section{Anopheles funestus insecticide susceptibility}

The mortalities induced by all insecticides on An. funestus are illustrated in Fig. 2. The mortality rate of An. gambiae Kisumu susceptible strain, used as a control was $100 \%$ for all tested insecticides, thus confirming the quality of the impregnated papers from Malaysia. In the negative control, mortality rates were below $5 \%$. Based on the WHO criteria, mortality data indicated that mosquitoes were highly resistant to five of the six tested insecticides i.e. malathion, DDT and all pyrethroids (deltamethrin, lambda-cyhalothrin, and permethrin). Mortality rates ranged from 23 to $74 \%$, which is far below the susceptibility threshold of $98 \%$ (Fig. 2; Table 1). For the pyrethroid groups, the mortality rate after observation time was $35 \%$ (25.7-45.1), $31 \%$ (22.1-41.0), and $23 \%(15.1-32.4)$ for lambda-cyhalothrin, deltamethrin, and permethrin, respectively. The mortality rate was $59 \%(48.7-68.7)$ and $74 \%$ (64.2-82.2) for DDT and malathion respectively. In contrast, mosquitoes were totally susceptible to bendiocarb (Carbamate) with $100 \%$ mortality was observed (Fig. 2; Table 1). Furthermore, $100 \%$ of the population tested was knockdown after $50 \mathrm{~min}$ of exposure to bendiocarb 


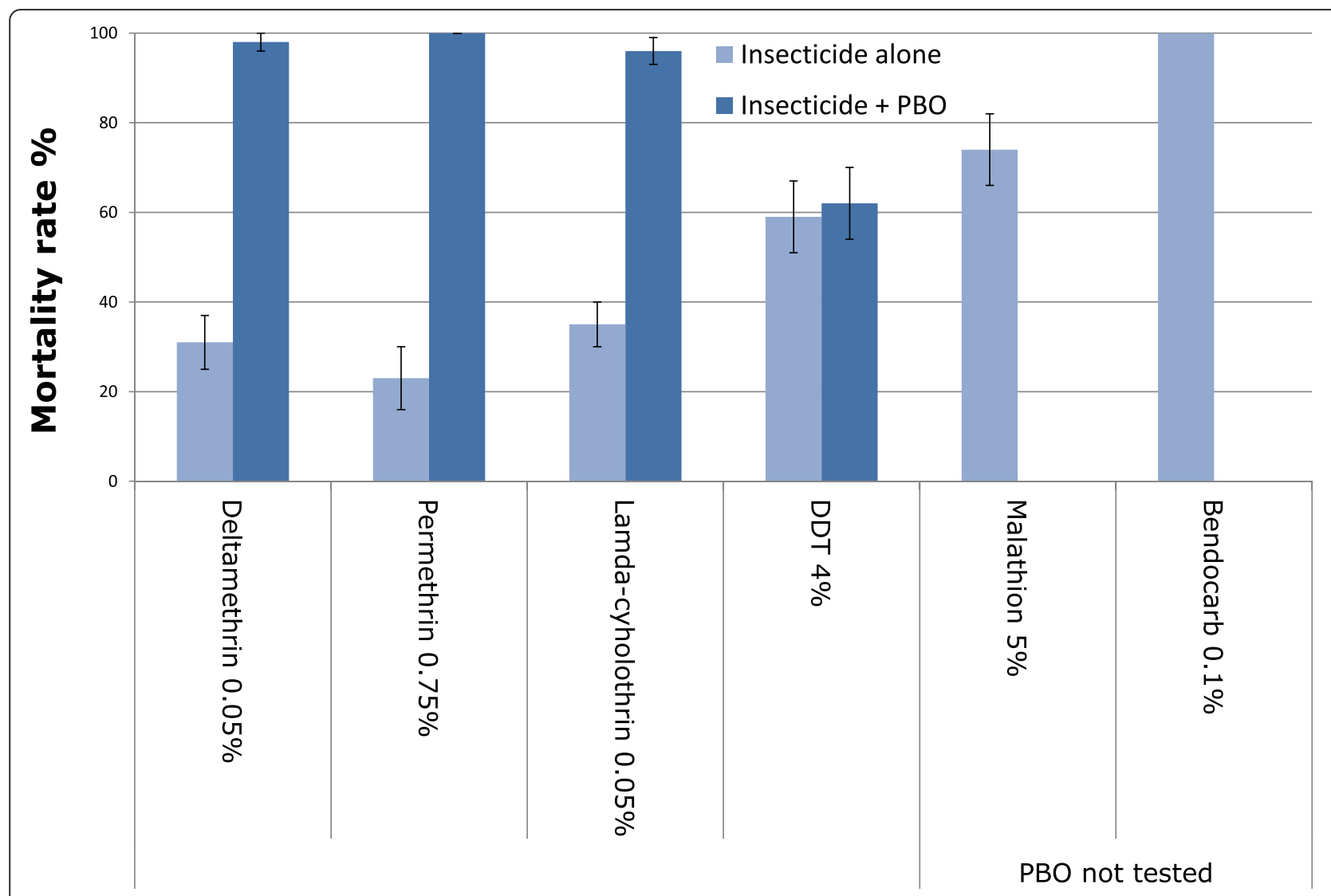

Fig. 2 Insecticide bioassay susceptibility test in An. funestus population from Gbanikola and effect of piperonyl butoxide (PBO) on the mortality of pyrethroids and DDT $24 \mathrm{~h}$ after exposition with $95 \%$ confidence interval (Cl)

with a short $\mathrm{KDT}_{50}$ time (23.5 $\mathrm{min}$ ) (21.8-25.2). Knockdown time was long for the pyrethroid groups (lambda-deltamethrin, lamda-cyhalothrin, permethrin), DDT and malathion with $\mathrm{KDT}_{50}$ higher than $50 \mathrm{~min}$ (Table 1).

\section{Effects of PBO synergist on Anopheles funestus}

Figure 2 shows the insecticidal activities of pyrethroids (permethrin, deltamethrin and lamda-cyhalothrin) and DDT before and after exposition to PBO synergist. Preexposure of An. funestus to PBO synergist significantly increases the mortality rate in pyrethroid groups. The mean mortality rate ranged from 23,31 and $35 \%$ before to 100 , 98 and $96 \%$ after exposure to permethrin, deltamethrin, and lamda-cyhalothrin, respectively (Fisher's exact test $P<0.0001)$. These results indicate the possible role of P450 activities to the resistance of An. funestus population. However, no such recovery of susceptibility was observed for DDT as there were no significance difference in mortality rate before $(59 \%)$ and after $(62 \%)$ PBO exposure (Fisher's exact test $P=0.724$ ). In view of these results, it would appear that oxidases (P450) are not the only metabolic resistance process in An. funestus population from Gbanikola.

Table 1 Bioassay susceptibility tests in An. funestus population from Gbanikola

\begin{tabular}{|c|c|c|c|c|c|c|}
\hline & Mortality \% & $95 \% \mathrm{Cl}$ & $\mathrm{KDT}_{50}$ & $95 \% \mathrm{Cl}$ & $\mathrm{KDT}_{95}$ & $95 \% \mathrm{Cl}$ \\
\hline Deltamethrin $0.05 \%$ & 31 & $22.1-41.0$ & 76.2 & $70.3-82.0$ & na & - \\
\hline Lambda-cyhalothrin $0.05 \%$ & 35 & $25.7-45.1$ & 69.4 & $66.5-72.3$ & na & - \\
\hline Permethrin $0.75 \%$ & 23 & $15.1-32.4$ & 71.9 & $69.0-74.7$ & na & - \\
\hline DDT $4 \%$ & 59 & $48.7-68.7$ & 51.7 & $48.5-54.9$ & na & - \\
\hline Malathion $5 \%$ & 74 & $64.2-82.2$ & 61.9 & $59.8-64.1$ & na & - \\
\hline Bendiocarb $0.1 \%$ & 100 & - & 23.5 & $21.8-25.2$ & 49.0 & $47.9-50.0$ \\
\hline
\end{tabular}

The mortality rate (\%) $24 \mathrm{~h}$ after exposition, 50 and $95 \%$ knockdown (KDT $\left.{ }_{50} \mathrm{KDT}_{95}\right)$ time (min) with $95 \%$ confidence interval (Cl), obtained on $100 \mathrm{An}$. funestus for each insecticide tested. na: not applicable 


\section{Biochemical activities of cytochrome P450, esterases and GST}

F1 An. funestus females unexposed to insecticides were biochemically analyzed for comparative enzyme activities to An. gambiae Kisumu susceptible strain in the absence of $A n$. funestus reference susceptible strain. Figure 3 shows the mean level enzymatic activity of cytochrome P450 (a), esterases (b), and GST (c) compared to Kisumu strain. All data from cytochrome P450 showed a significant enzymatic activity (expressed in cytochrome P450 units) compared to the susceptible Kisumu strain reference (Wilcoxon test $P=0.0017$ ) (Fig. 3a). A significant correlation between cytochrome P450 enzymatic activity and bioassay mortality data (all pyrethroids) was observed (Kruskal-Wallis test $P<0.005$ ) indicating that a metabolic resistance mechanism through the cytochrome $\mathrm{P} 450$ genes is operating in the $A n$. funestus population from Gbanikola. A significant increased esterase esterases activity (using $\beta$-naphthyl acetate) was observed in the $A n$. funestus population compared to the Kisumu susceptible strain (Wilcoxon test $P=0.006$ ). The mean level enzymatic activity ranged from 0.031 to 0.303 with an average of 0.167 for $A n$. funestus while it ranged from 0.03 to 0.151 with an average of 0.09 for the Kisumu susceptible strain (Fig. 3b). A significant increase level of GST activity (using glutathione and 1-chloro-2,4-dinitrobenzene) was observed in the $A n$. funestus population from Gbanikola compared to the An. gambiae susceptible Kisumu strain (Wilcoxon test $P=0.0002$ ). The GST activity in the $A n$. funestus population from Gbanikola ranged from 0.79 to 3.77 with an average of 2.15 while it ranged from 0.5 to 2.11 in the Kisumu strain with an average of 1.18 (Fig. 3c).

\section{Discussion}

This study is the first in the CAR to investigate the resistance status of the Anopheles population using WHO protocol [25]. The level and type of insecticide resistance present in the $A n$. funestus population from
Gbanikola, Bangui to six insecticide molecules in WHO diagnostic doses was investigated. Despite the full susceptibility to bendiocarb, the population of An. funestus showed a high metabolic resistance to malathion, DDT and pyrethroids (deltamethrin, lamda-cyhalothrin and permethrin). However, although this was the first study done in the CAR, insecticide resistance in wild An. funestus populations is not a new phenomenon in Africa. Metabolic resistance of An. funestus to pyrethroids and DDT is widespread in the Afrotropical region particularly in Mozambique [17], Uganda [28], southern Africa [29], Benin [18] and Ghana [20].

So far no $k d r$ resistance mechanism has yet been found in An. funestus [17, 18]. By comparison, this mutation is present in $A n$. gambiae population in most parts of Africa and practically in all species (An. gambiae, An. coluzzii, $A n$. arabiensis) and often with both types $k d r$-east and $k d r$-west $[13,21,30]$. The use of pyrethroids and DDT as pesticides for agriculture and for bed-net treatment have both been recognized as factors responsible for the natural selection of resistant mosquitoes in sub-Saharan Africa [31-33]. The emergence and rapid spread of insecticide resistance in Anopheles population may impair the effectiveness of malaria vector control based on the use of LLINs and IRS and therefore threaten the sustainability of the current strategies for decreasing malaria transmission $[11,34]$. The reduced effectiveness of insecticides coincides with an important international effort to increase bed-net coverage in African countries in order to control malaria transmission [13]. Also, in this study we have not investigated the insecticide resistance origin in Gbanikola district. However, there is high agricultural activity (rice cultivation) in Gbanikola. We believe that the use of pesticides in these fields constitute a possible source of resistance. Nevertheless, resistance in An. funestus population, one of the major African malaria vectors, is important enough to advise the national malaria control programme to improve management of insecticide resistance in the Anopheles population.

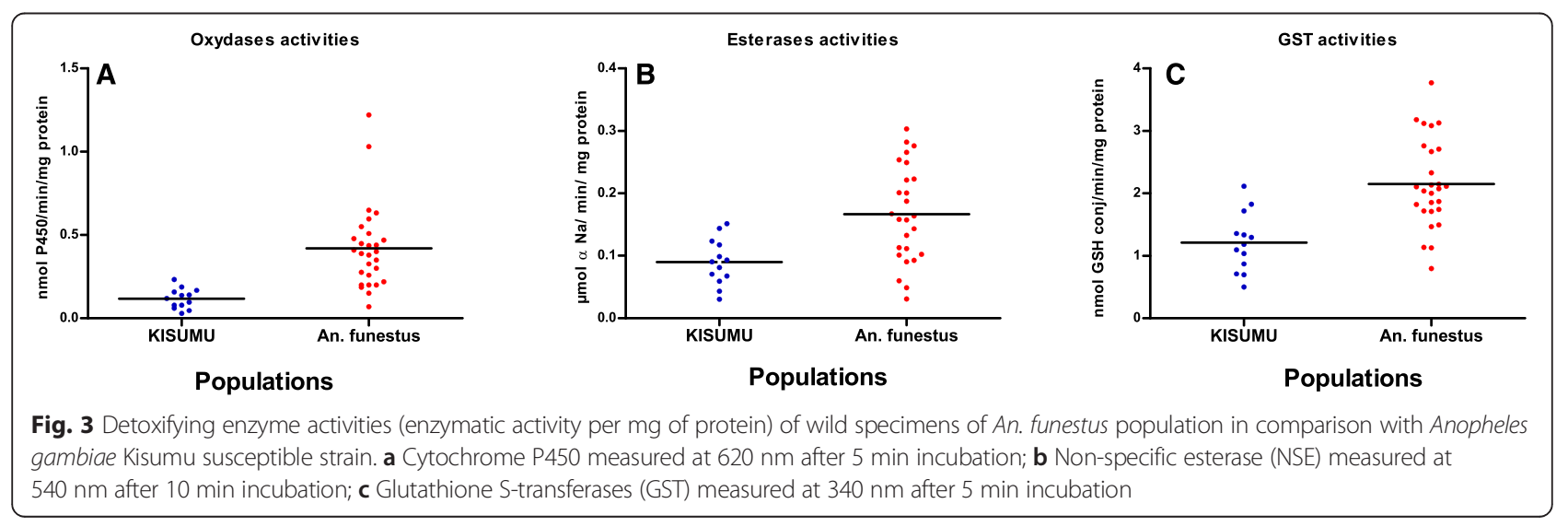


Pre-exposure to $\mathrm{PBO}$ synergist has restored the full susceptibility to pyrethroids and not to DDT suggesting the involvement of other metabolic resistance mechanisms beyond that demonstrated by the $\mathrm{PBO}$ synergist action. Elsewhere, it has been clearly shown that the metabolic mechanism alone can drive the mosquito resistance to pyrethroid insecticides [18, 35]. However, the effect of PBO synergist is more marked with deltamethrin than with the lamda-cyhalothrin, suggesting the involvement of monooxygenase enzymes [36].

Biochemical analysis measuring the enzymatic activity of cytochrome P450, esterases and GST of the An. gambiae Kisumu and An. funestus strains showed that cytochrome P450 activity was significantly higher in $A n$. funestus than the Kisumu strain. Secondly, there were strong esterases and GST activities in the An. funestus population compared to the Kisumu strain. Thus, our data clearly indicate that the pyrethroid resistance in Gbanikola is driven by the involvement of cytochrome $\mathrm{P} 450$. Biochemical tests also indicate that GST could be involved in DDT resistance and that esterases could be involved in malathion resistance. Hence this study shows the presence of several types of metabolic resistance mechanisms within the same An. funestus population, which is not without consequence in the future development of vector control strategies, especially for targeted malaria control $[10,37]$. The combined effect of elevated cytochrome P450 and esterases activity in pyrethroid resistance Anopheles mosquitoes has previously been reported [17, 38]. In contrast, the study conducted in Pahou, Benin by Djouaka et al. [18] indicated a high level of insecticide resistance to pyrethroid, DDT, and bendiocarb and total susceptibility to malathion.

Considering our own and previous studies $[17,18,20$, $28,39]$, it is clear that the most common resistance mechanism in An. funestus is metabolic. This result highlights once again the high variability in insecticide resistance patterns and resistance mechanisms in $A n$. funestus population. Pyrethroid and DDT resistance mechanisms are likely not associated with target resistance as no $k d r$ mutations associated with resistance to both insecticides was detected. However, further studies are needed to investigate the role of CYP6P9a and CYP6P9b, the two main resistance genes associated with pyrethroid resistance [19].

In terms of vector control research, it is crucial to take into account these different aspects of insecticide resistance. Such resistance has serious implications for malaria control because pyrethroids are the main insecticides recommended by WHO for vector control, especially for bed-net treatment $[40,41]$. However the choice of future insecticide in vector control by the CAR national malaria control programme must be reexamined in view of our results.
The bioassays conducted in this study show that $A n$. funestus in Gbanikola, Bangui are totally susceptible to bendiocarb which could be a good alternative for IRS in this region. Thereby, in a context marked by a difficult political situation from every point of view, it has added the thorny problem of insecticide resistance. In a country where control structures against malaria exist in name only, it is obvious that substantial efforts must be made by the international community for better management of the issues related to fighting malaria [42].

\section{Conclusion}

For the first time in the CAR, an entomological study has provided data on the insecticide susceptibility status of An. funestus. High levels of pyrethroid and DDT resistance were observed in Mbanikola district, and constitute a challenge for resistance management strategies. Therefore, this study provides data to the international community on insecticide resistance in this part of Africa where political, economic and security issues have prevented such research. Despite these difficulties, further research is urgently needed to inventory the insecticide susceptibility status of the An. funestus population in all CAR regions including An. gambiae (s.l.); insecticide resistance could rapidly compromise the successes of malaria control programs throughout the region.

\section{Competing interests \\ The authors declare that they have no competing interests. \\ Authors' contributions \\ MON planned and designed the study with the substantial contributions of MK. MOS and TO performed field and laboratory work. MON and MOS performed data analysis, interpreted the results and drafted the manuscript. SPW and MK reviewed and provided comments to the manuscript with the substantial contribution of MA. MON provided scientific supervision of the study. All authors read and approved the final manuscript.}

\section{Acknowledgements}

We thank Dr Bill Brogdon (CDC-Atlanta) and Dr Vincent Richard (IP, New Caledonia) for helpful comments on biochemical data and interpretation. Special thanks to Dr Paul Bassell to review previous versions of this manuscript. We thank Mr. Patrick Sanchez for coordinating teams' security at the Institut

Pasteur of Bangui. We also thank the residents of Gbanikola for their cooperation throughout the study.

\section{Funding}

This work was supported by the Division International of Institut Pasteur Paris (DI- IPIN/RIIP-G4 Group Leader) to Ousmane NDIATH. The funders had no role in study design, data collocation and analysis, decision to publish, or preparation of the manuscript.

\section{Author details \\ ${ }^{1}$ G4 Malaria Group Institut Pasteur in Bangui, Bangui, Central African Republic. ${ }^{2}$ Faculté des Sciences et Techniques, Université d'Abomey Calavi, Cotonou, Bénin. ${ }^{3}$ Faculté des Sciences et Techniques, Laboratoire de Biologie Animale Appliquée et de Biodiversité, Université de Bangui, Bangui, Central African Republic. ${ }^{4}$ Virology Department, Institut Pasteur in Bangui, Bangui, Central African Republic. ${ }^{5}$ Centre de Recherche Entomologique de Cotonou (CREC), Cotonou 06 BP 2604, Bénin.}

Received: 22 January 2016 Accepted: 14 April 2016 Published online: 25 April 2016 


\section{References}

1. WHO. World Malaria Report 2014. Geneva: World Health Organization; 2014. http://www.who.int/malaria/publications/world_malaria_report_2014/wmr2014-no-profiles.pdf.

2. MSF. Rapport Médecins Sans Frontières 2015. République Centrafricaine. 2015. http://www.msf.fr/actualite/dossiers/republique-centrafricaine-crisesilencieuse.

3. MSF. Rapport Médecins Sans Frontières. Une Crise silencieuse République Centrafricaine. 2011. http://www.msf.fr/sites/www.msf.fr/files/ddp-rca-frlow-res_1.pdf.

4. Manirakiza A, Njuimo SP, Le Faou A, Malvy D, Millet P. Availability of antimalarial drugs and evaluation of the attitude and practices for the treatment of uncomplicated malaria in Bangui, Central African Republic. East Afr J Public Health. 2009;6(3):292-5.

5. Manirakiza A, Serdouma E, Heredeibona LS, Djalle D, Madji N, Moyen M, Soula G, Le Faou A, Delmont J. Rational case management of malaria with a rapid diagnostic test, Paracheck $P f(R)$, in antenatal health care in Bangui, Central African Republic. BMC Public Health. 2012;12:482.

6. WHO. Insecticide-treatedmosquito nets: a WHO position statement. Global malaria programme. Geneva: World Health Organization; 2007. http://www. who.int/malaria/world_malaria_report_2011/9789241564403_eng.pdf.

7. Greenwood BM. Control to elimination: implications for malaria research. Trends Parasitol. 2008:24(10):449-54.

8. WHO. Pesticides and their applications for the control of vectors and pests of public health importance. WHO Geneva, WHO/CDS/NTD/WHOPES/ GCDPP; 2006. http://apps.who.int/iris/bitstream/10665/69795/10661/WHO_ CDS_NTD_WHOPES_GCDPP_12006.10661_eng.pdf.

9. Curtis CF. Insecticide treated mosquito nets. Trop Doct. 1998;28(1):63.

10. Greenwood B, Koram K. Malaria control in Africa: progress but still much to do. Lancet. 2014;383(9930):1703-4.

11. Trape JF, Tall A, Diagne N, Ndiath O, Ly AB, Faye J, Dieye-Ba F, Roucher C, Bouganali C, Badiane A, et al. Malaria morbidity and pyrethroid resistance after the introduction of insecticide-treated bednets and artemisinin-based combination therapies: a longitudinal study. Lancet Infect Dis. 2011; 11(12):925-32

12. PMI. President's Malaria Initiative Country Insecticide Susceptibility Summaries. 2015.

13. Ndiath MO, Sougoufara S, Gaye A, Mazenot C, Konate L, Faye O, Sokhna C, Trape JF. Resistance to DDT and pyrethroids and increased kdr mutation frequency in An. gambiae after the implementation of permethrin-treated nets in Senegal. PLoS One. 2012;7(2):e31943.

14. Corbel V, Akogbeto M, Damien GB, Djenontin A, Chandre F, Rogier C, Moiroux N, Chabi J, Banganna B, Padonou GG, et al. Combination of malaria vector control interventions in pyrethroid resistance area in Benin: a cluster randomised controlled trial. Lancet Infect Dis. 2012;12(8):617-26.

15. Ngoagouni C, Kamgang B, Manirakiza A, Nangouma A, Paupy C, Nakoune E, Kazanji M. Entomological profile of yellow fever epidemics in the Central African Republic, 2006-2010. Parasit Vectors. 2012:5:175

16. Fontenille D, Simard F. Unravelling complexities in human malaria transmission dynamics in Africa through a comprehensive knowledge of vector populations. Comp Immunol Microbiol Infect Dis. 2004 27(5):357-75.

17. Cuamba N, Morgan JC, Irving H, Steven A, Wondji CS. High level of pyrethroid resistance in an Anopheles funestus population of the Chokwe District in Mozambique. PLoS One. 2010;5(6):e11010.

18. Djouaka R, Irving H, Tukur Z, Wondji CS. Exploring mechanisms of multiple insecticide resistance in a population of the malaria vector Anopheles funestus in Benin. PLoS One. 2011;6(11):e27760.

19. Mulamba C, Riveron JM, Ibrahim SS, Irving H, Barnes KG, Mukwaya LG, Birungi J, Wondji CS. Widespread pyrethroid and DDT resistance in the major malaria vector Anopheles funestus in East Africa is driven by metabolic resistance mechanisms. PLoS One. 2014;9(10):e110058.

20. Okoye PN, Brooke BD, Koekemoer LL, Hunt RH, Coetzee M. Characterisation of DDT, pyrethroid and carbamate resistance in Anopheles funestus from Obuasi, Ghana. Trans R Soc Trop Med Hyg. 2008;102(6):591-8.

21. Ranson H, N'Guessan R, Lines J, Moiroux N, Nkuni Z, Corbel V. Pyrethroid resistance in African anopheline mosquitoes: what are the implications for malaria control? Trends Parasitol. 2011:27(2):91-8.

22. IPB. Annual Institut Pasteur Bangui Report. Bangui: Institut Pasteur of Bangui; 2013. p. 62. http://www.pasteur.fr/sites/www.pasteur.fr/files/rapport-activites2013-ip-bangui.pdf.
23. Gillies MT, De Meillon B. The Anophelinae of Africa South of the Sahara (Ethiopian zoogeographical region). Johannesburg: Publications of the South Africa Institute for Medical Research; 1968. p. 343.

24. Cohuet A, Simard F, Toto JC, Kengne P, Coetzee M, Fontenille D. Species identification within the Anopheles funestus group of malaria vectors in Cameroon and evidence for a new species. Am J Trop Med Hyg. 2003;69(2):200-5.

25. WHO. Test procedures for insecticide resistance monitoring in malaria vector mosquitoes WHO/CDS/CPC/MAL/D. Geneva: World Health Organization; 2013. http://apps.who.int/iris/bitstream/10665/80139/10661/ 9789241505154 eng.pdf.

26. Brogdon WG, McAllister JC, Vulule J. Heme peroxidase activity measured in single mosquitoes identifies individuals expressing an elevated oxidase for insecticide resistance. J Am Mosq Control Assoc. 1997;13(3):233-7.

27. Hemingway J, Brogdon WG. Techniques to Detect Insecticide Resistance Mechanisms (Field and Laboratory Manual). In: Document WHO/CDS/CPC/ MAL/986. Geneva: World Health Organ; 1998.

28. Morgan JC, Irving H, Okedi LM, Steven A, Wondji CS. Pyrethroid resistance in an Anopheles funestus population from Uganda. PLoS One. 2010;5(7):e11872.

29. Brooke BD, Kloke G, Hunt RH, Koekemoer LL, Temu EA, Taylor ME, Small G, Hemingway J, Coetzee M. Bioassay and biochemical analyses of insecticide resistance in southern African Anopheles funestus (Diptera: Culicidae). Bull Entomol Res. 2001;91(4):265-72.

30. Diabate A, Baldet T, Chandre F, Guiquemde RT, Brengues C, Guillet P, Hemingway J, Hougard JM. First report of the kdr mutation in Anopheles gambiae M form from Burkina Faso, west Africa. Parassitologia. 2002; 44(3-4):157-8.

31. Chandre F, Darrier F, Manga L, Akogbeto M, Faye O, Mouchet J, Guillet P. Status of pyrethroid resistance in Anopheles gambiae sensu lato. Bull World Health Organ. 1999;77(3):230-4.

32. Czeher C, Labbo R, Arzika I, Duchemin JB. Evidence of increasing Leu-Phe knockdown resistance mutation in Anopheles gambiae from Niger following a nationwide long-lasting insecticide-treated nets implementation. Malar J. 2008;7:189.

33. Diabate A, Baldet T, Chandre F, Akoobeto M, Guiquemde TR, Darriet F, Brengues C, Guillet P, Hemingway J, Small GJ, et al. The role of agricultural use of insecticides in resistance to pyrethroids in Anopheles gambiae s.I. in Burkina Faso. Am J Trop Med Hyg. 2002;67(6):617-22.

34. Sokhna C, Ndiath $M O$, Rogier C. The changes in mosquito vector behaviour and the emerging resistance to insecticides will challenge the decline of malaria. Clin Microbiol Infect. 2013;19(10):902-7.

35. Witzig C, Parry M, Morgan JC, Irving H, Steven A, Cuamba N, Kerah-Hinzoumbe C, Ranson H, Wondji CS. Genetic mapping identifies a major locus spanning P450 clusters associated with pyrethroid resistance in kdr-free Anopheles arabiensis from Chad. Heredity (Edinb). 2013;110(4):389-97.

36. Riveron JM, Irving H, Ndula M, Barnes KG, Ibrahim SS, Paine MJ, Wondji CS. Directionally selected cytochrome P450 alleles are driving the spread of pyrethroid resistance in the major malaria vector Anopheles funestus. Proc Natl Acad Sci U S A. 2013;110(1):252-7.

37. Feachem RG, Sabot OJ. Global malaria control in the 21 st century: a historic but fleeting opportunity. JAMA. 2007;297(20):2281-4.

38. Fonseca-Gonzalez I, Quinones ML, McAllister J, Brogdon WG. Mixed-function oxidases and esterases associated with cross-resistance between DDT and lambda-cyhalothrin in Anopheles darlingi Root 1926 populations from Colombia. Mem Inst Oswaldo Cruz. 2009:104(1):18-26.

39. Casimiro S, Coleman M, Mohloai P, Hemingway J, Sharp B. Insecticide resistance in Anopheles funestus (Diptera: Culicidae) from Mozambique. J Med Entomol. 2006;43(2):267-75.

40. RBM. Technical support network for insecticide-treated netting materials: scaling-up insecticide-treated netting programmes in Africa. In: Roll Back Malaria, editor. A strategic framework for coordinated national action, 14. Geneva: WHO; 2002. p. 1-5.

41. Zaim M, Aitio A, Nakashima N. Safety of pyrethroid-treated mosquito nets, Med Vet Entomol. 2000:14(1):1-5.

42. Feachem $R$, Sabot $O$. A new global malaria eradication strategy. Lancet. 2008:371(9624):1633-5. 